\title{
Relationship Between Personality and Handwriting Using Eysenck Test
}

\author{
Ashraf Karami \\ Masters of General Psychology, Islamic Azad University of Tabriz, Tabriz, Iran \\ Email address: \\ ashraf_karamii@yahoo.com
}

\section{To cite this article:}

Ashraf Karami. Relationship Between Personality and Handwriting Using Eysenck Test. International Journal of Psychological and Brain Sciences. Vol. 2, No. 2, 2017, pp. 28-39. doi: 10.11648/j.ijpbs.20170202.11

Received: January 11, 2017; Accepted: January 29, 2017; Published: March 10, 2017

\begin{abstract}
This study attempts to examine ways of writing (handwriting) include: pen pressure, the character size, the distance between the rows, words and letters, the base line, stand line, punctuation of punctual letters, with introvert and extrovert personality, emotional stability- instability (neuroticism) and psychotic features associated with them and study the relationship between these variables using the Eysenck personality questionnaire (adult). The sample used in this study consists of 68 people among the members of community (Miyaneh city in Iran, regardless of their job and position) randomly including 36 women and 32 men. In this study Eysenck Tests questionnaire is used in the form of 90 questions. Chi-squared test results show that there is a significant relation with $99 \%$ confidence level between all studied variables in handwriting and the kind of personality characteristics. According to the results, personality of people couldn't be realized based on just one variable and different variables of personality must taking into account in the handwriting judge. In general, it may be judged that (a) In society, number of people with unstable extrovert personality is more; (b) the amount of instable people is more than stable and (c) the number of extroverts is more than introverts.
\end{abstract}

Keywords: Handwriting, Personality Character, Eysenck Test, Graphology, Chi-squared Test

\section{Introduction}

Nowadays, wide variety of mental tests used for character recognition which have their advantages and disadvantages. Some are long and tedious and some have ability to present pretended answers and some are less objective. It seems that "graphology" compared to other projective tests hasn't more sources of error and disadvantages. In fact, there is no data or literature that shows the efficiency and accuracy of this method is less [1]. The prominence of this measuring personality method is availability, ease of implementation and ability to inhibit confounding factors such as pretending (good or bad) in the subjects. However, the interpretation of results unlike easy implementation is often complex, difficult and requires the history of subject [1].

Graphology, which exists both as art and as science, is the analysis of handwriting. Handwriting is a complex, overlearned motor skill in which biomechanical and cognitive processes contribute to the spatial form and the kinematic features of the handwritten product. In addition to communicating the meanings of written words, graphology was founded on the dubious premise that handwriting can express features of a person's personality, mentality, and capability [15].

Cronje and Roets [4] studied the graphology research from 1975 before performing empirical research for ability evaluation to use graphology in psychology assessment and showed that obtained data from graphology in assessment could be very negative or useful. The first thing that drew attention was that available research was done in four key areas, namely the use of handwriting psychology at:

a Assessment of personality aspects and emotional versatility

b Prediction of job or academic performance

c Recognition of individual potential for management

d Selection of employees

Bouadjenek et al. [3] developed a robust prediction of the writer's gender, age range and handedness. First, three prediction systems using SVM classifier and different features that are pixel density, pixel distribution and gradient local binary patterns, are proposed. Since each system performs differently to the others, a combination method that aggregates a robust prediction from individual systems, is 
proposed. This combination uses Fuzzy MIN and MAX rules to combine membership degrees derived from predictor outputs according to their performances, which are modeled by Fuzzy measures.

In handwriting analysis, graphologist commonly consider many factors such as the font, size, formations, curvature, distance between uppercase and lowercase letters, signatures uniformity, angle, pen pressure, intersections, slopes, margins, connectors, spacing between words, baselines, height and width of the letters and etc., which represents aspects related to the author's personality traits [2].

This study attempts to examine ways of writing (handwriting manuscript) including pen pressure, the character size, the distance between the rows, words and letters, the base line, stand line, punctuation of punctual letters, with introvert and extrovert personality, emotional stability- instability (neuroticism) and psychotic features associated with them and study the relationship between these variables using the Eysenck personality questionnaire (adult).

\subsection{The Hypothesis of Study}

Conjectures that can be raised about the relationship variables considered in above questions and the expected results of this paper expressed as follows:

[a] There is a relationship between pen pressure on paper and personality.

[b] There is a relationship between the character size and characteristics of personality.

[c] There is a relationship between distance (lines, words and letters) and personality characteristics.

[d] There is a relationship between baseline and personality characteristics.

[e] There is a relationship between the stand lines and personality characteristics.

[f] There is a relationship between the punctuation of punctual characters in the handwriting and personality characteristics.

\subsection{Operational Definition of Used Variables}

According to Eysenck's personality test, acquired individual score is compared with mean and standard deviation of Eysenck Personality Questionnaire based on their age for men and women and then the stability and instability, neuroticism, discrete-orientation psychotherapy and individual introversion and extraversion is calculated and judged.

I Emotional instability: achieving score above the average standard deviation based on Table 1, which indicates that the person absorb to the people who have emotionality, unstable and neuroticism trait and describe with words such as nervous, moody, irritable, restless, irritable, depressed, unreasonable, uncompromising, aggressive [9].

Emotional stability: in front of the instability, creating strong, with words such as calm, carefree, lively, pioneer is known as moderate and stable. Achieving score to the average standard deviation based on Table 1 [9].

II Neuroticism (factor $\mathrm{N}$ ); symbol of neuroticism is achieving score greater than $50 \%$ in scale $\mathrm{N}$ (neuroticism or emotional instability) (Table 1). Emotional imbalance, aggressive reaction, complaints of physical pain and anxiety are characteristics of these people. Score lower than $50 \%$ is sign of emotional stability, stability of behavior and emotional balance, relaxation and weaknesses of aggressive behavior [10].

III Discrete-Oriented Psychotherapy (Factor P); raw score above the average (see Table 1), indicates that a person tends to discrete-oriented psychotherapy. These are isolated individuals, apathy, impulsive, egocentric, aggressive, hardened, creative and oblivious to others [9].

IV Introversion: score below the average including standard deviation (Table 1) in scale E, shows the introspective person. In this people, inactivity, withdrawal, depression and responsibilities is obvious [10].

$\mathrm{V}$ Extraversion (Factor E): score higher than the average including standard deviation in scale $\mathrm{E}$ (Table 1) shows the extraversion person, which is representative of activity, sociability, humor, optimism, and self-expression is risk acceptance and assertive [10].

VI Desire for social acceptance (Factor L): L measures the sensitivity and tendency to socially acceptable. L higher than average including the standard deviation (Table 1), indicate the person who put himself in hardness to be accepted by others; this means that do anything just to be accepted by others! $\mathrm{L}$ is also considered as polygraph factor [9]. If $\mathrm{L}$ is too high (above 80 percent), it will not have good interpretation value [10].

VII Pen pressure: two notes are necessary in measuring the pressure: a thick and solid line representing the pen pressure is classified into the following levels: very low, low, medium, high, very high, high pressure with sleeping letters to the left and inequality pressure [1].

VIII Character size: height of letters, the preferred style of author in life, its width defines the personal required space and is measured in millimeters and divided into the following degrees: very coarse, coarse, medium, fine and ultrafine [1].

IX Distance

a Distance between the rows express as moderate distances, low distances between rows, high distance of rows and very high distance of rows and different distances.

b Distance between words: in fact words distance shows the amount of distance tendency with others. Dependent people put the words in narrow distances, and express as distance equal distance of 
words, unequal distance of words, narrow distance of words, high distance of words and very high distance of words.

c Distance between letters: the distance determine based on narrow and long and balancing distance between letters.

X X. Baseline: The line which helps to measure the amount of line slope and can be measured by two ways of slope and shape $[1,7]$.

XI XI. Stand line: vertical segments in some letters like "ط، ظ، ا، م،... (in Persian) which stand and indicate the degree of emotional connection with others [1].

XII XII. Punctuation: punctuation includes letters with points like “..." (in persian) and style of punctuation: punctuation in the correct place for people who think very carefully and cautiously; high punctuation for who are perfectionist and ambitious; low punctuation for who has material and positive thoughts, shallow pessimism and weakness; thrown around punctuation for who are quick thinking, bored, and carefree that jumps from one object to another. Single point like very short segments indicates excessive stimulation, motion, offensive and aggressive movements. Conversion of single point to circle is often indicative of selfishness and lack of conscience [1].

Table 1. Mean and standard deviation of Eysenck Personality Questionnaire for Iranian women and men over 16 years old [9].

\begin{tabular}{|c|c|c|c|c|c|c|c|c|c|}
\hline & \multirow[t]{2}{*}{ Age } & \multicolumn{4}{|c|}{ Mean } & \multicolumn{4}{|c|}{ Standard Deviation } \\
\hline & & $\mathbf{P}$ & $\mathbf{E}$ & $\mathbf{N}$ & $\mathbf{L}$ & $\mathbf{P}$ & $\mathbf{E}$ & $\mathbf{N}$ & $\mathbf{L}$ \\
\hline \multirow{8}{*}{ Women } & 16 & 5.15 & 11.6 & 14.7 & 11.20 & 1.58 & 1.64 & 2.2 & 2.35 \\
\hline & 17 & 5.05 & 12.23 & 15.17 & 11.92 & 1.37 & 1.81 & 2.02 & 1.98 \\
\hline & 18 & 5.39 & 12.3 & 15.66 & 14.94 & 1.38 & 1.81 & 2 & 2.14 \\
\hline & 19 & 5.34 & 12.5 & 16.13 & 12 & 1.52 & 1.82 & 2.02 & 2.08 \\
\hline & $20-29$ & 5.04 & 9.89 & 14.99 & 12.97 & 1.35 & 1.8 & 2.35 & 1.98 \\
\hline & $30-39$ & 4.7 & 13.74 & 13.79 & 13.65 & 2.65 & 1.55 & 5.31 & 2.81 \\
\hline & $40-49$ & 4.88 & 12.05 & 13.85 & 13.85 & 2.71 & 3.37 & 4.5 & 3.65 \\
\hline & $50-59$ & 5.13 & 11.26 & 13.16 & 4.7 & 3.24 & 3.94 & 5.7 & 3.82 \\
\hline \multirow{8}{*}{ Men } & 16 & 6.55 & 13.49 & 13.71 & 11.76 & 1.75 & 1.64 & 2.03 & 2.04 \\
\hline & 17 & 6.43 & 12.95 & 12.98 & 11.7 & 1.5 & 1.66 & 2.31 & 2.9 \\
\hline & 18 & 6.02 & 12.26 & 13.41 & 12.28 & 2.78 & 1.6 & 2.3 & 2.18 \\
\hline & 19 & 6 & 12.21 & 13.6 & 11.7 & 1.48 & 1.27 & 2.38 & 1.95 \\
\hline & $20-29$ & 5.61 & 11.72 & 12.16 & 11.68 & 1.98 & 1.52 & 2.15 & 1.99 \\
\hline & $30-39$ & 7.7 & 11.94 & 11.7 & 12.02 & 2.13 & 1.43 & 1.78 & 1.87 \\
\hline & $40-49$ & 8.9 & 11 & 11.4 & 11.24 & 2.03 & 1.45 & 1.82 & 3.28 \\
\hline & $50-59$ & 5.3 & 10.11 & 12.51 & 10.5 & 1.77 & 0.4 & 1.79 & 1.58 \\
\hline
\end{tabular}

\section{Literature Review}

\subsection{Eysenck Personality Factor}

British psychologist Hans Eysenck achieved two personality factor of introversion - extroversion and emotional stability - instability (in his own words neuroticism) with similar method of Raymond Cattell [8,11].

A study explored the relationships between certain handwriting characteristics, intelligence, occupational interests, and personality as assessed by the EPI. In a sample of women subjects with high 'Lie' scores, significant correlations between a combination of handwriting features and certain aspects of the Eysenck Personality Inventory were obtained. Considerably different relationships, however, were observed in a matched group of subjects with lower than average 'Lie' scores [5].

\subsection{Introversion - Extroversion}

According to Eysenck, extroverts and introverts tend to realistic and idealistic visions respectively. If they are conservative, introverts will tend to religious beliefs and attitudes, while extroverts will tend to vision of counting offenders penalty for death and whip and opposition to racial integration and humiliate the colored people.

\subsection{Neuroticism}

These people spend their time to do worthless behavior, especially behavior that has been internalized. A key element of neuroticism is inability to decision making. Most of psychologists believe that kind of hereditary preparation is necessary for neuroticism that pushes all of person's behavior to this preparation [10].

\subsection{Handwriting Analysis}

\section{Baseline}

The base line represents the writer feedback to the past, present and future. Psychological energy that a writer uses to achieve its objectives is its ability for

Decision making, prosperity and enjoying the life. Baseline specifies the author's pessimism or optimism. Table 2 shows the personality characteristic associated with each type of baseline. Given that studied language in this paper is Persian, writing and forms are from right to left, unlike English. 
Table 2. Baselines and related personality traits [1].

\begin{tabular}{|c|c|c|}
\hline Line shape & Line type & Personality characteristic \\
\hline & Upward baseline & $\begin{array}{l}\text { Ambitious, energetic, motivated, faith in the future, lively, simultaneous busy multi-task, happy, always } \\
\text { successful, with perseverance, self-confidence, good feeling about themselves, may be unrealistic, optimistic, } \\
\text { always likes to be busy. }\end{array}$ \\
\hline & Downward baseline & $\begin{array}{l}\text { Pessimistic, feeling fear, grief and burnout, disappointment or failure overall view to life, critic, depressed, } \\
\text { discouraged, violence thinking, tired, ill, weak. }\end{array}$ \\
\hline & $\begin{array}{l}\text { Undifferentiated } \\
\text { baseline }\end{array}$ & Slope of the line in different rows of horizontal paper is upward and downward. Erratic, Fierce. \\
\hline & $\begin{array}{l}\text { Convex arcuate } \\
\text { baseline }\end{array}$ & $\begin{array}{l}\text { At first line slope is upward and then gradually is downward. Symbol of persons who start a work energetic } \\
\text { but become tired in the middle and maybe leave it. They have no perseverance and companionship. }\end{array}$ \\
\hline & & At first visual line is downward, but gradually trend line become ascendant. \\
\hline & & Symbol of persons who well done works. \\
\hline & baseline & They like beginning and performing works. \\
\hline & & $\begin{array}{l}\text { They haven't enough confidence first, but gradually overcome the negative mold, and finally find positive } \\
\text { feedbacks. }\end{array}$ \\
\hline$\sim$ & $\begin{array}{l}\text { Fix baseline with } \\
\text { descending words }\end{array}$ & $\begin{array}{l}\text { The general line slope is zero (horizontal), but words and phrases are overlay mounted and has direction } \\
\text { from the top line to the tangent line (see figure), battles with depression and lack of self-confidence }\end{array}$ \\
\hline & $\begin{array}{l}\text { Fix baseline with } \\
\text { ascending words }\end{array}$ & $\begin{array}{l}\text { The general line slope is zero (horizontal), but words and phrases are overlay mounted and has direction } \\
\text { from the top line to the tangent line (see figure), Heat and eager, impatient, too much optimistic towards life }\end{array}$ \\
\hline$\simeq$ & Horizontal baseline & Behavior management, balancing act, stable, sensible, reliable, realistic, well structured. \\
\hline
\end{tabular}

II. Form of stand line

Characteristics related to different kinds of stand line form in individual handwriting are presented in Table 3.

Table 3. Standing line and related personality characteristics [1].

\begin{tabular}{|c|c|c|}
\hline Line shape & Line type & Personality characteristic \\
\hline & $\begin{array}{l}\text { Right angle (88- } \\
96 \text { degree) }\end{array}$ & $\begin{array}{l}\text { Stable, strong, self-contained, cold-blooded, isolated, thinker, unsocial, wisdom overcome on heart and emotions, } \\
\text { selfish, arrogant, cynicism, cautious, realistic, calm, curious, fair, hopeful, balanced, cynical and skeptical, strong, } \\
\text { unsentimental }\end{array}$ \\
\hline & $\begin{array}{l}\text { Inclined to left } \\
\text { (96-118 degree) }\end{array}$ & $\begin{array}{l}\text { Agreeableness, emotional, skilled, brave and fearless, with heating, Affective, moderate expression of emotions, } \\
\text { extroverts, kind, facing towards the future, feeling sympathy, communicative, needy for social exchange and } \\
\text { diversity logical, without stress, independent self-image from others, emotional, social, spontaneous, lack of } \\
\text { selfishness }\end{array}$ \\
\hline & $\begin{array}{l}\text { Curved to left } \\
(120-135 \text { degree })\end{array}$ & $\begin{array}{l}\text { Emotional, warm-blooded, unwilling to be alone, expressing emotions, kind, impulsive, intertwined, interested in } \\
\text { human society, jealous, judging from the emotional, sensitive, social, sense of sympathy, restless, needy to be } \\
\text { approved, a lack of self-control }\end{array}$ \\
\hline & $\begin{array}{l}\text { Full curved to left } \\
\text { (135-165 degree) }\end{array}$ & $\begin{array}{l}\text { Dependent on others, emotional, excited allowed, expressing emotions, unstable and erratic, reckless, impatient, } \\
\text { impulsive, restless, jealous, lack of discipline, needy for support, reactive, hypersensitivity, romantic, self- } \\
\text { awareness, thoughtlessness, unpredictability, chaos and instability }\end{array}$ \\
\hline & $\begin{array}{l}\text { Lie down to left } \\
\text { (165-180 degree) }\end{array}$ & Hysterical, excessive stimulation, outbursts of emotion, aggressive jealousy, strange \\
\hline & $\begin{array}{l}\text { Inclined to right } \\
(60-88 \text { degree })\end{array}$ & $\begin{array}{l}\text { Objective, cautious, controlled, determined, diplomatic relationships with others, difficulty in trusting others, } \\
\text { self-contained, independent, inhibited, insight, introverted, subjective, emotional inhibition, shyness, lack of } \\
\text { sympathy, conservative, hesitant, thoughtful, quiet }\end{array}$ \\
\hline & $\begin{array}{l}\text { Curved to left ( } 45- \\
60 \text { degree) }\end{array}$ & $\begin{array}{l}\text { Fears of being in crowds, defensive, lack of interest in human society, evaded the facts, fears of an independent } \\
\text { future, inhibited, insecure, introverted, inhibited emotions, engrossed and immersed in himself }\end{array}$ \\
\hline & $\begin{array}{l}\text { Full curved to } \\
\text { right }(15-30 \\
\text { degree })\end{array}$ & $\begin{array}{l}\text { Artificial, defensive, mentally ill, fears of the future, sense of lack of interest and rejection, inhibited, un- } \\
\text { superficial, alone, selfish, hypersensitivity, retrospect, self-awareness, suspicious to others, unable to social } \\
\text { communication, unhappy, withdrawn, arrogant, arrogance, cynical, indifferent, depressed }\end{array}$ \\
\hline & $\begin{array}{l}\text { Lie down to right } \\
(0-15 \text { degree })\end{array}$ & Fear of life, fear of others, lack of self-control, probably suicide, self-criticism, unhappy, secluded \\
\hline & $\begin{array}{l}\text { Tolerance between } \\
\text { inclined and } \\
\text { curved to left }\end{array}$ & Interested to others but hesitant to this feeling \\
\hline & $\begin{array}{l}\text { Tolerance between } \\
\text { inclined and } \\
\text { curved to right }\end{array}$ & Distrusted in others, maybe he is not aware of it \\
\hline & $\begin{array}{l}\text { Tolerance from } \\
\text { inclined to left to } \\
\text { curved to right }\end{array}$ & Try to maintain its adequacy \\
\hline & All direction & $\begin{array}{l}\text { Unbiased, mental disruption, Affective, lack of ability in decision making, nervous, irritable, worried, chaotic, } \\
\text { instable, unpredictable, versatile, erratic, strange, tail erratic, capricious }\end{array}$ \\
\hline
\end{tabular}

\subsection{Statistical Sample}

The sample used in this study consists of 68 people among the members of community (Miyaneh city in Iran, regardless of their job and position) randomly including 36 women and 32 men. 


\section{Research Method}

Correlation between two variables has start from a range of -1 continues to +1 , this value called correlation coefficient. Correlation Coefficient calculates by the chi-square method as $\mathrm{C}$ adaptive coefficient. $\mathrm{C}$ is an indicator which calculates the correlation between two nominal variables setting up in a contingency table. Since determination of the variables relations is concerned, this study is correlational and chisquare test is applied.

\subsection{Measuring Tools and Scoring Method}

In this study Eysenck Tests questionnaire is used in the form of 90 questions.

Pay attention to the table of mean and standard deviation factors (Table 1) for interpretation of achieved scores. According to the scores for $\mathrm{N}$ and $\mathrm{E}$, one of the following modes for individual can be considered:

Instable extrovert: High $\mathrm{N}+$ High $\mathrm{E}$

Stable extrovert: Low N + High E

Stable introvert: Low $\mathrm{N}+$ High $\mathrm{E}$

Instable introvert: High $\mathrm{N}+$ Low $\mathrm{E}$

If a person achieves high scores of $\mathrm{P}$ and low score of $\mathrm{E}$ and $\mathrm{N}$, in fact will be a healthy and creative person. Majority of neurotic patients achieve high score of $\mathrm{N}$ and low score of E. Against criminals and anti-social persons achieve high scores in all three factors of $\mathrm{E}, \mathrm{P}$ and $\mathrm{N}[9,13]$.

High score $\mathrm{P}$ in educated persons, can show the opposition with the existing discipline. $\mathrm{P}$ and $\mathrm{E}$ in men are usually higher.

\subsection{Determination of Questionnaire Reliability and Validity}

In order to determine the reliability and validity of the questionnaire, Eysenck it performed on a single group at two different times and obtained its validity and reliability. Internal validity coefficient for men was, $\mathrm{P}=0.78, \mathrm{E}=0.90$, $\mathrm{N}=0.88, \mathrm{~L}=0.82$ and for women $\mathrm{P}=76, \mathrm{~N}=0.85, \mathrm{~L}=0.79$. In the Iranian sample reliability coefficient with retest method and interval of two months is reported as follows: $\mathrm{P}=0.92$, $\mathrm{N}=0.88, \quad \mathrm{~N}=0.89, \mathrm{P}=0.72$, which indicates very high reliability and acceptability $[9,12]$.

\subsection{Research Implementation Method}

Variables in this paper were pen pressure, the character size, the distance between the rows, words and letters, base line, stand line, punctuation of punctual words and the score of individuals in the scales of Eysenck Personality Test.

Handwriting of persons for each variable was measured with mentioned method, and then correlation calculated between handwriting and scales of Eysenck Personality Test. After performing the test and answering the questions, a selected text from Golestan Sa'di about 5 rows offers to persons to write it with their typical handwritings; then results analyzed.

\subsection{Statistical Method}

In this study, all required descriptive and inferential statistics methods are applied. Charts were used to present the results. Several variables were investigated: Person's handwriting (variables was mentioned previously) and person's score in the scales of E, N, P Eysenck Personality test to examine their relationship by chi-square test. Applied formula is as follow:

$$
\chi^{2}=\sum \frac{(O-E)^{2}}{E}
$$

$\chi^{2}=$ Chi-square

$\mathrm{O}=$ Observed or measured frequency

$E=$ Expected or assumptive frequency

According to the research hypotheses, the following formula for the correlation calculation is used ( $\mathrm{c}$ is number of subjects):

$$
C=\sqrt{\frac{\chi^{2}}{\chi^{2}+n}}
$$

\section{Results and Discussion}

\subsection{Descriptive Statistical Analysis}

Descriptive methods usually use to determine and express the characteristics or information collected by the researchers. In the following frequency and percentage of subjects responds to studied variables are presented and chart of each variable is compared with variable classes in each Eysenck Personality factors.

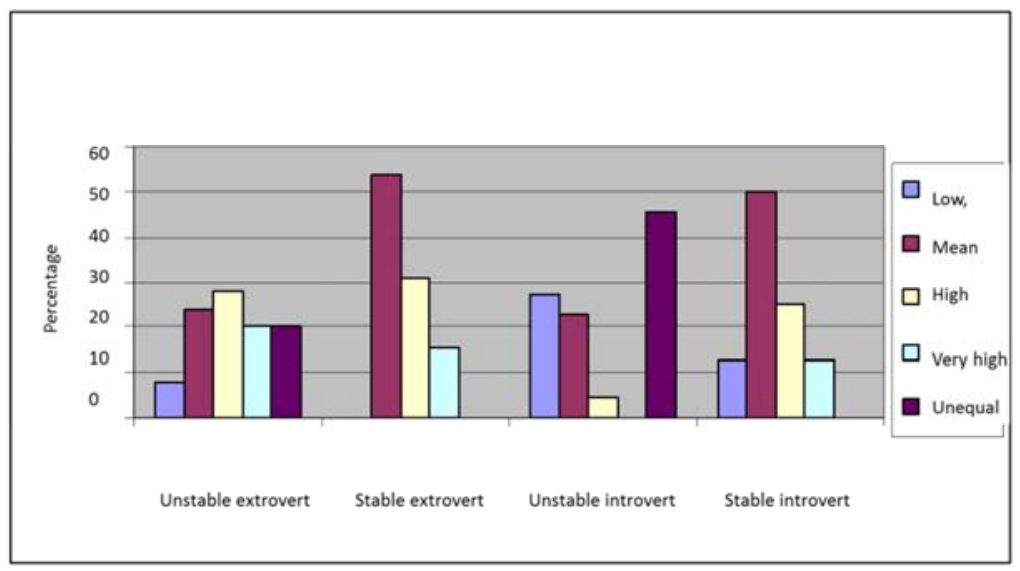

Figure 1. Percentage of subjects responds to pen pressure variable according to Eysenck personality factors. 


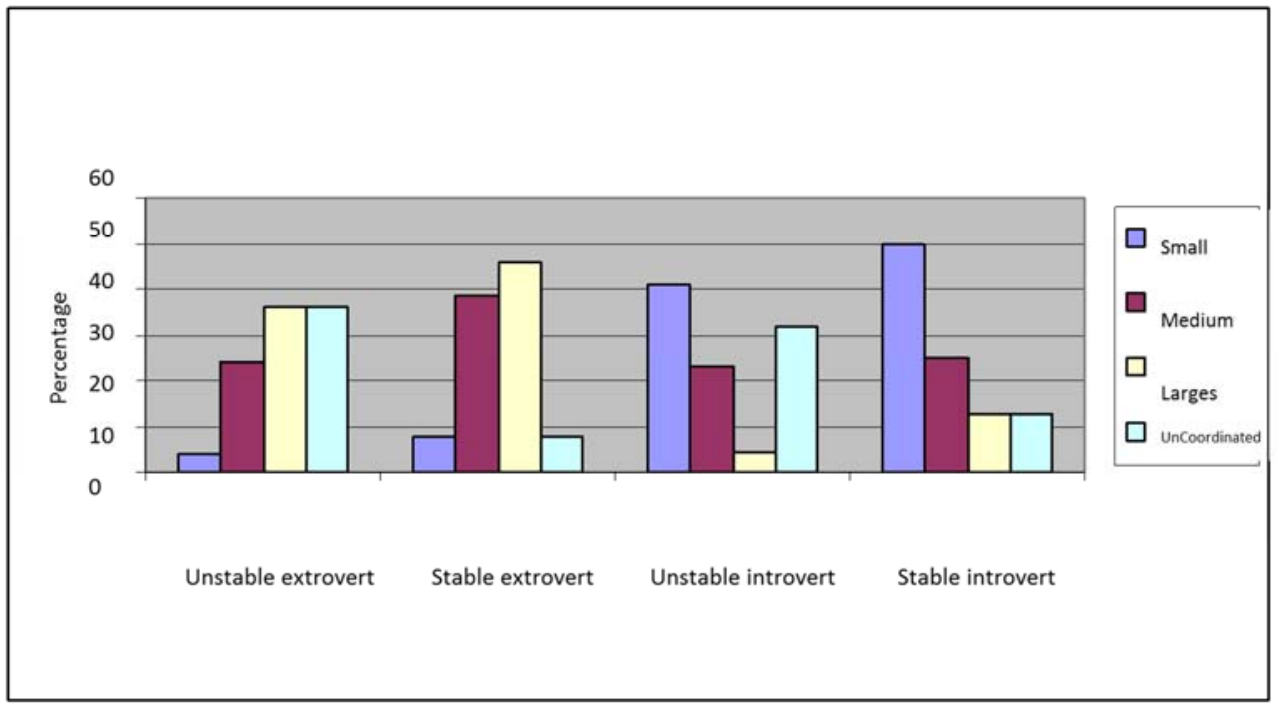

Figure 2. Percentage of subjects responds to characters size variable.

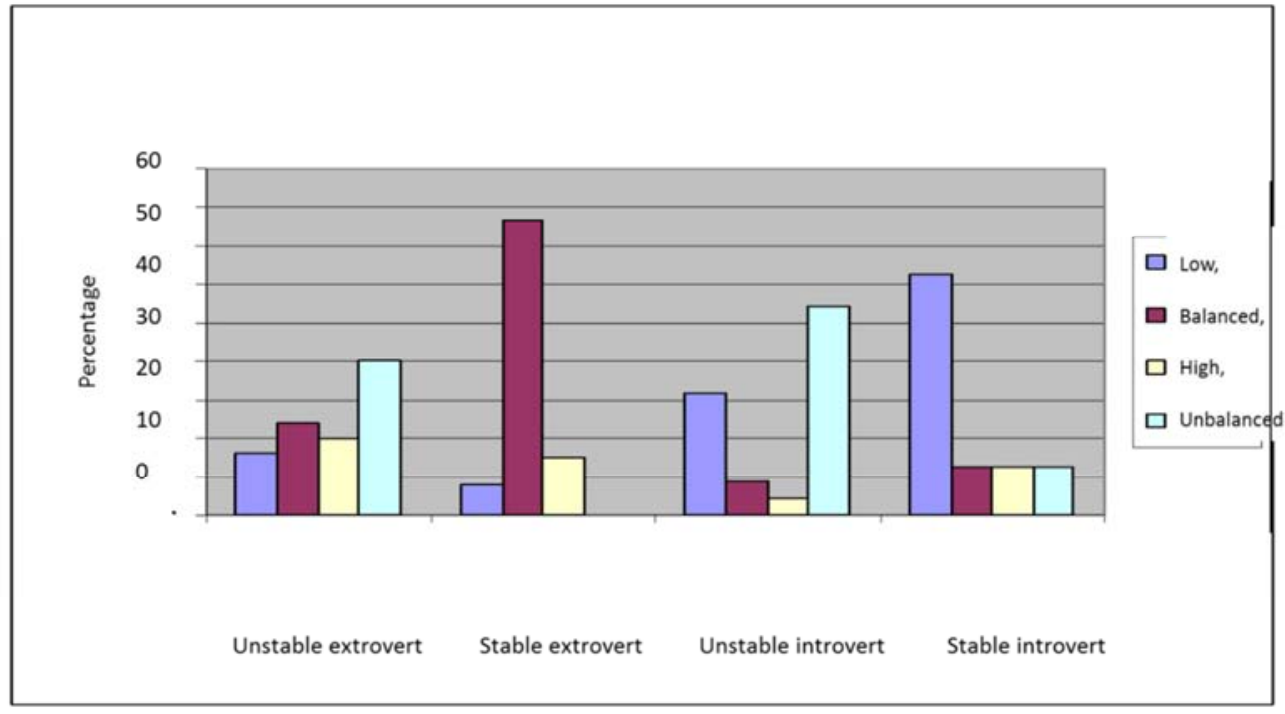

Figure 3. Percentage of subjects responds to rows distance variable.

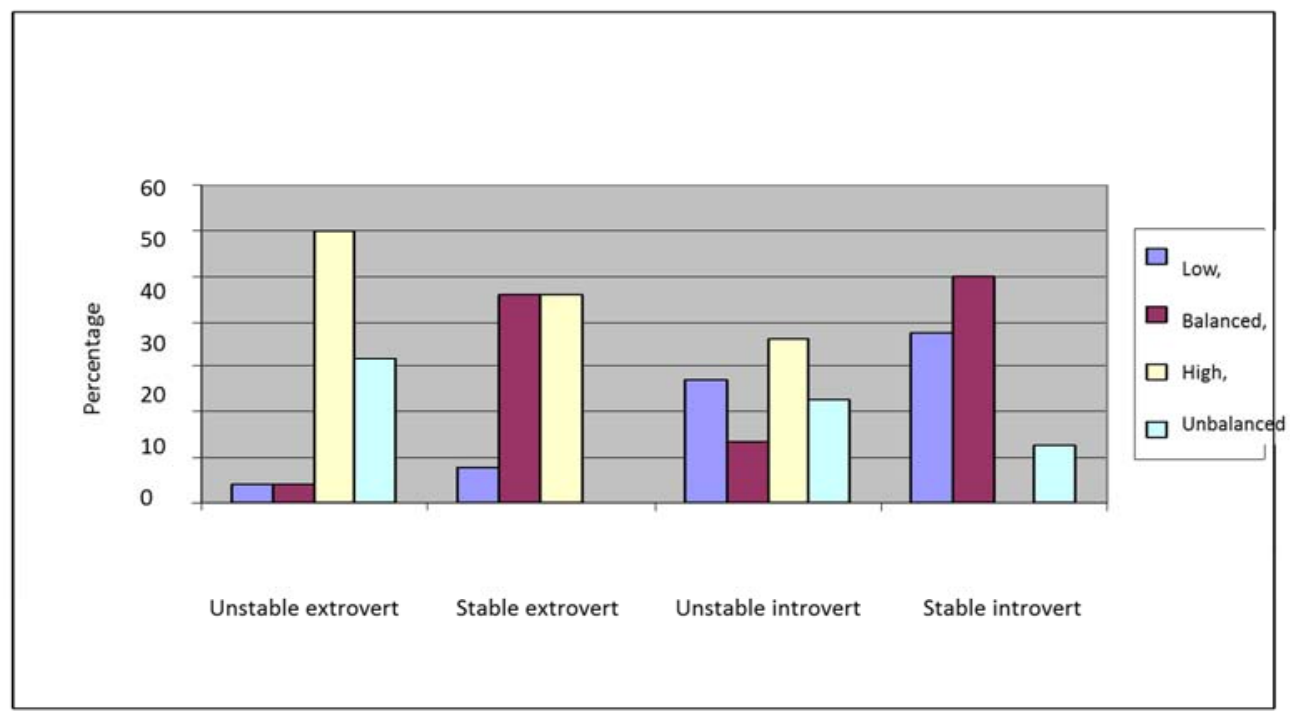

Figure 4. Percentage of subjects responds to words distance variable. 


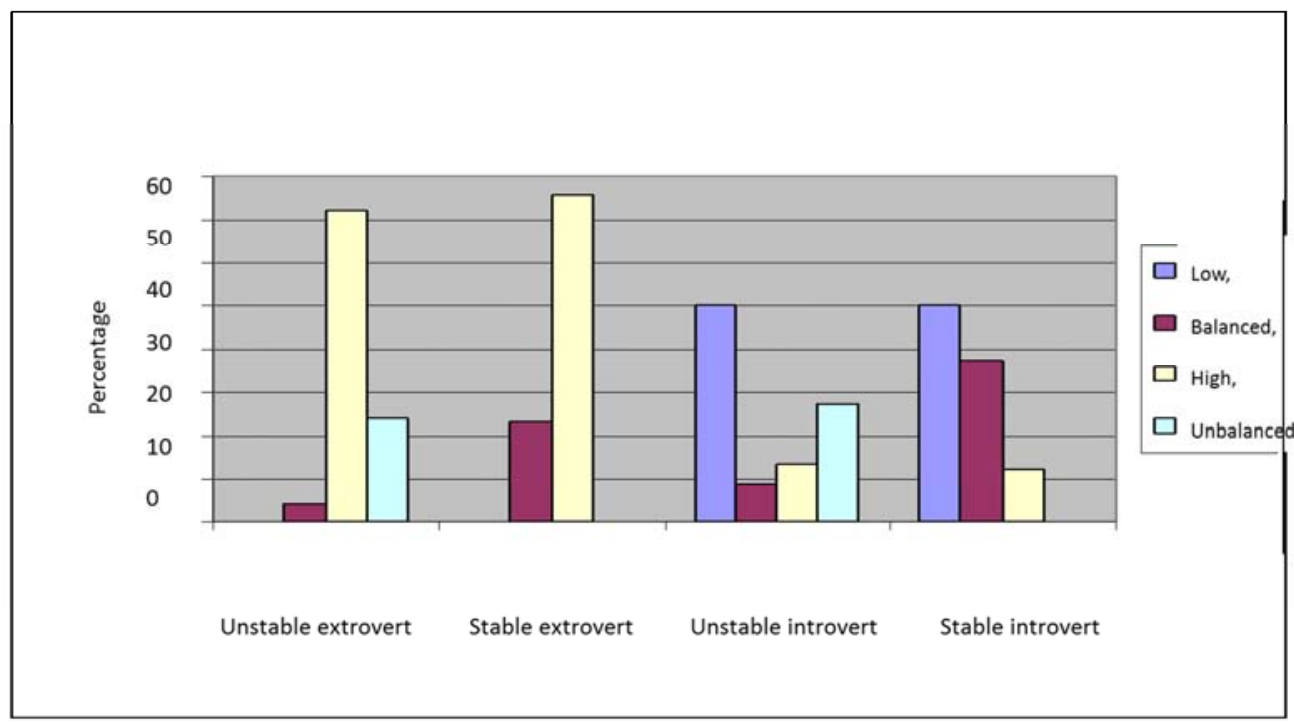

Figure 5. Percentage of subjects responds to letters distance variable.

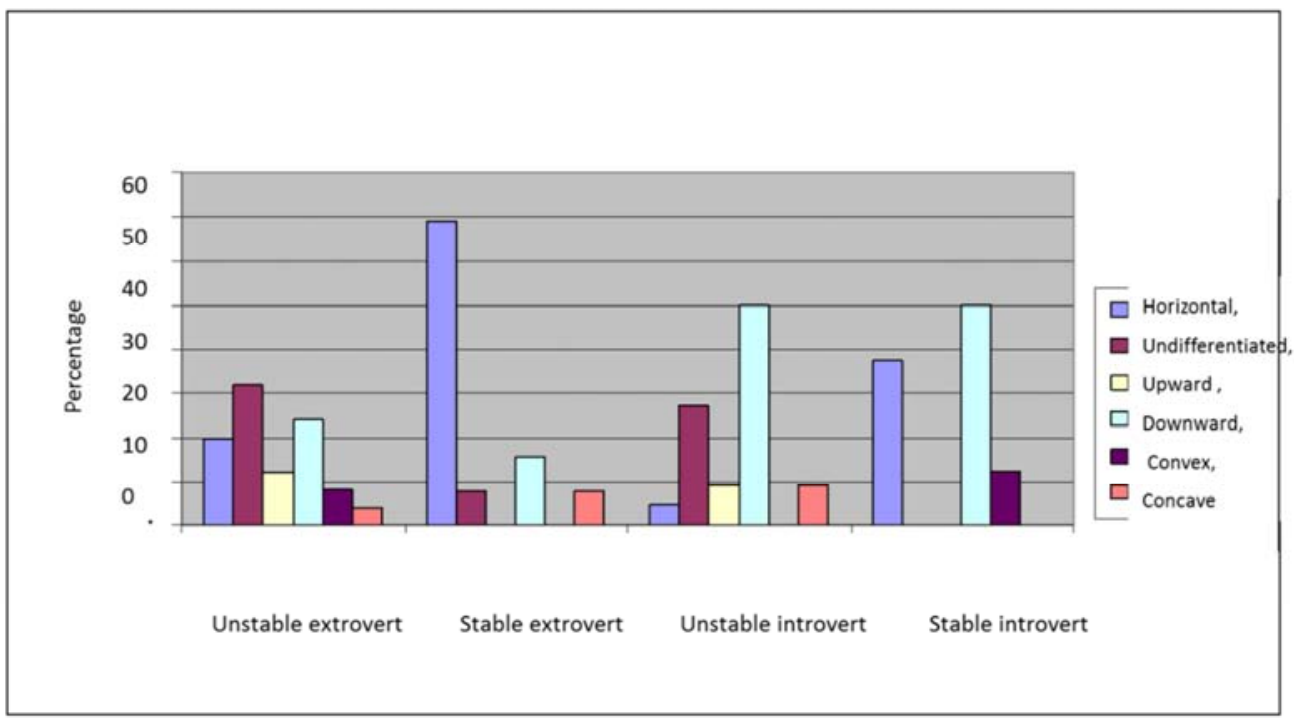

Figure 6. Percentage of subjects responds to baseline variable.

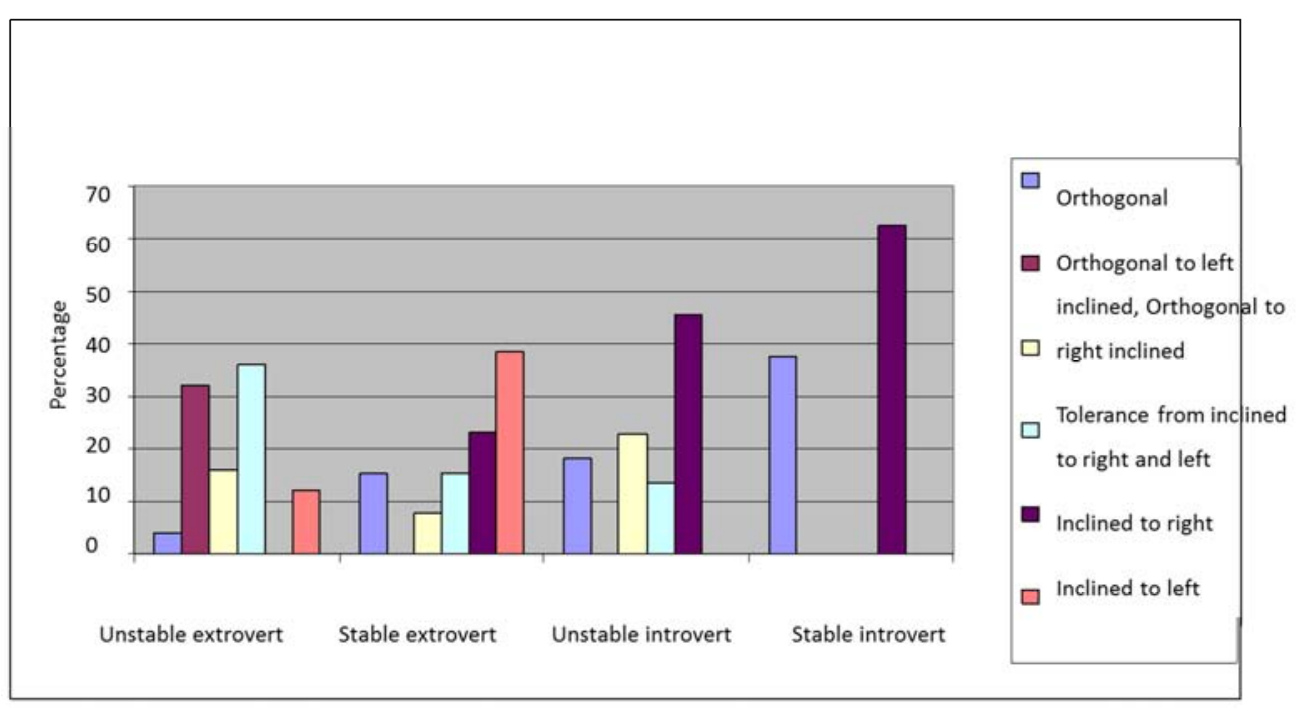

Figure 7. Percentage of subjects responds to stand line variable. 


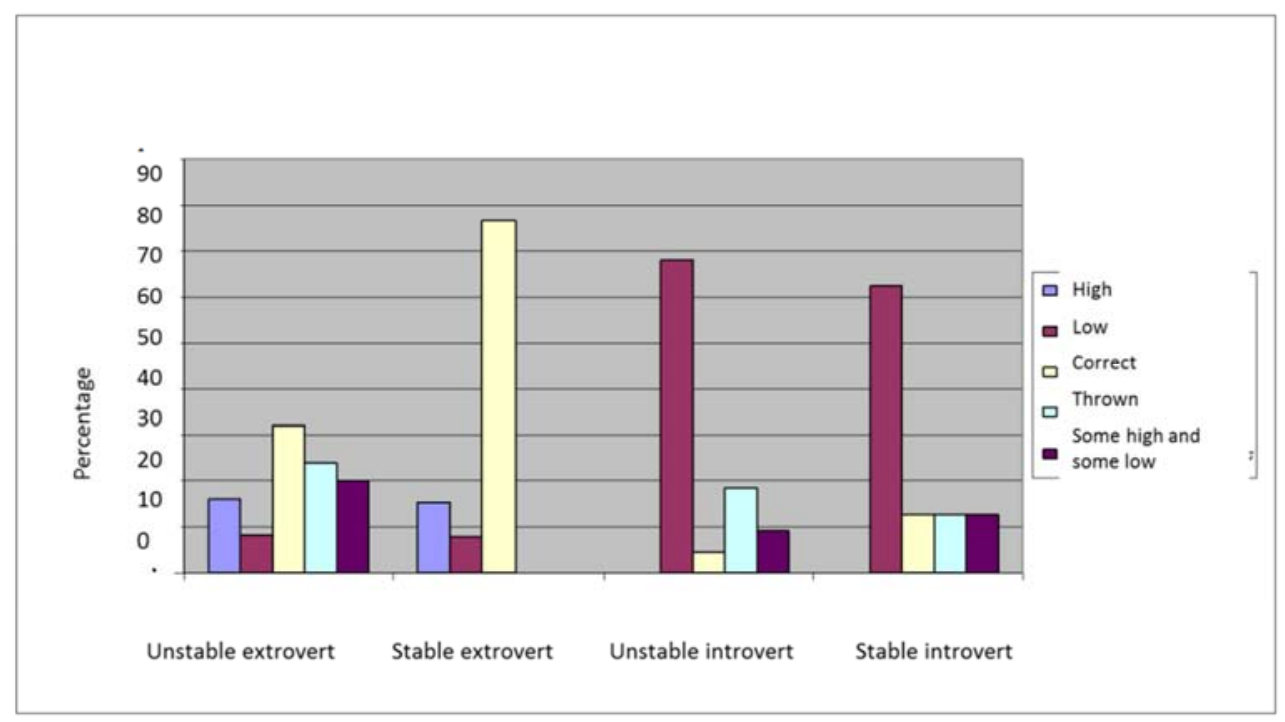

Figure 8. Percentage of subjects responds to punctuation variable.

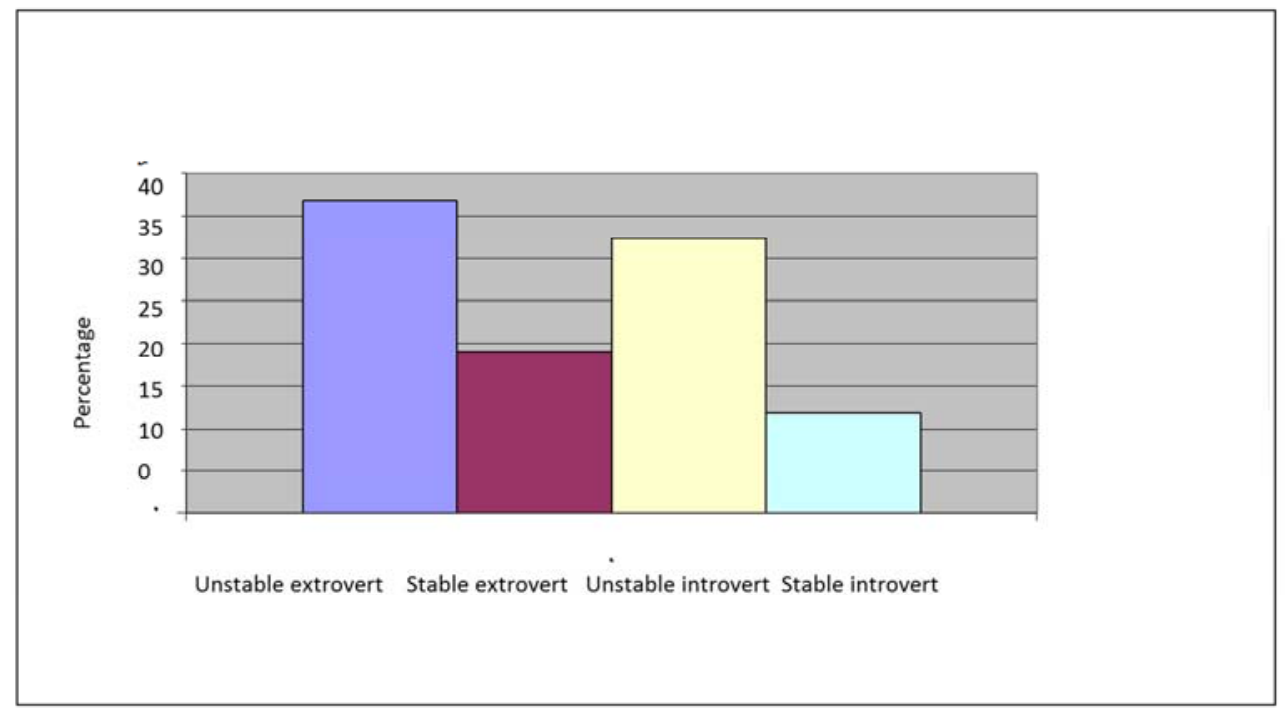

Figure 9. The percentage of individuals classified in four characters based on Eysenck questionnaires.

\subsection{Inferential Analysis}

The tables for calculation of variables test and correlation are listed in next page separately. Table G (Chi-square distribution) is used to investigate the significant levels [6].

Table 4. Chi-square for pen pressure variable.

\begin{tabular}{lllllllllllllllllll}
\hline & \multicolumn{1}{c}{ Unstable extrovert } & \multicolumn{4}{c}{ Stable extrovert } & \multicolumn{4}{c}{ Unstable introvert } & \multicolumn{3}{c}{ Stable introvert } \\
\hline Classes & $\mathbf{O}$ & $\mathbf{E}$ & $\boldsymbol{O}-\boldsymbol{E}$ & $\frac{(\boldsymbol{O}-\boldsymbol{E})^{\mathbf{2}}}{\boldsymbol{E}}$ & $\mathbf{O}$ & $\mathbf{E}$ & $\boldsymbol{O}-\boldsymbol{E}$ & $\frac{(\boldsymbol{O}-\boldsymbol{E})^{\mathbf{2}}}{\boldsymbol{E}}$ & $\mathbf{O}$ & $\mathbf{E}$ & $\boldsymbol{O}-\boldsymbol{E}$ & $\frac{(\boldsymbol{O}-\boldsymbol{E})^{\mathbf{2}}}{\boldsymbol{E}}$ & $\mathbf{O}$ & $\mathbf{E}$ & $\boldsymbol{O}-\boldsymbol{E}$ & $\frac{(\boldsymbol{O}-\boldsymbol{E})^{\mathbf{2}}}{\boldsymbol{E}}$ & $\boldsymbol{O}$ & $\mathbf{E}$ \\
\hline Low & 2 & 3.3 & -1.3 & 0.512 & - & 1.72 & -1.72 & 1.72 & 6 & 2.9 & 3.1 & 3.31 & 1 & 1 & 0 & 0 & 9 & 9 \\
Mean & 6 & 8.1 & -21 & 0.55 & 7 & 4.2 & 2.8 & 1.87 & 5 & 7.1 & -2.1 & 0.62 & 4 & 2.6 & 1.4 & 0.75 & 22 & 22 \\
High & 7 & 5.1 & 1.9 & 0.71 & 4 & 2.7 & 1.3 & 0.63 & 1 & 4.52 & -3.52 & 2.74 & 2 & & 0.32 & 0.06 & 14 & 14 \\
Very high & 5 & 2.6 & 2.4 & 2.21 & 2 & 1.32 & 0.68 & 0.35 & - & 2.26 & -2.26 & 2.26 & - & & -0.82 & 0.82 & 7 & 7 \\
unequal & 5 & 5.9 & -0.9 & 0.13 & - & 3.03 & -3.03 & 3.03 & 10 & 5.22 & 4.78 & 4.38 & 1 & 1.9 & 0.9 & 0.42 & 16 & 16 \\
Sum & 25 & 25 & & 4.11 & 13 & 13 & & 7.6 & 22 & 22 & & 13.31 & 8 & 8 & & 2.05 & 68 & 68 \\
\hline
\end{tabular}

Correlation coefficient is calculated as follows:

$$
C=\sqrt{\frac{\chi^{2}}{\chi^{2}+n}}=\sqrt{0.284}=0.53
$$

$$
\chi^{2}=\sum \frac{(O-E)^{2}}{E}=27.07
$$

Domain of Freedom $(\mathrm{df})=($ number of rows- 1$)($ number of column-1) 


$$
d f=(5-1)(4-1)=4 \times 3=12
$$

Based on Table $\mathrm{G} \propto=0.01 \rightarrow \chi^{2}=26.22$

Calculated Chi-square is greater than table Chi-square, so research hypothesis is accepted with $99 \%$ confidence level. According to Table 4 and accuracy in variable classes, pen pressure in extraversions was moderate to high and in most of cases is high. High pen pressure in introverts is rare and in most cases is low to moderate. In unstable introverts is unequal and less and in stable introverts is average. Overall, pen pressure in introverts is low, in extroverts is high, in stable individuals is middle and in unstable individuals is unequal.

Table 5. Chi-square for character size variable.

\begin{tabular}{|c|c|c|c|c|c|c|c|c|c|c|c|c|c|c|c|c|c|c|}
\hline & Un & stable & xtrover & & & Ible ex & rovert & & Un & able in & overt & & & able in & trovert & & tota & al \\
\hline $\begin{array}{l}\text { character size } \\
\text { classes }\end{array}$ & $\mathbf{O}$ & $\mathbf{E}$ & $O-E$ & $\frac{(\boldsymbol{O}-E)^{2}}{E}$ & $\mathbf{O}$ & $\mathbf{E}$ & $O-E$ & $\frac{(\boldsymbol{O}-\boldsymbol{E})^{2}}{E}$ & 0 & $\mathbf{E}$ & $O-E$ & $\frac{(\boldsymbol{O}-E)^{2}}{E}$ & $\mathbf{O}$ & $\mathbf{E}$ & $O-E$ & $\frac{(\boldsymbol{O}-E)^{2}}{E}$ & 0 & $\mathbf{E}$ \\
\hline Small & 1 & 5.51 & -4.51 & 3.69 & 1 & 2.87 & -1.87 & 1.21 & 9 & 4.85 & 4.15 & 3.55 & 4 & 1.77 & 2.23 & 2.8 & 15 & 15 \\
\hline Medium & 6 & 6.62 & -0.62 & 0.06 & 5 & 3.44 & 1.56 & 0.7 & 5 & 5.83 & -0.83 & 0.1 & 2 & 2.11 & -0.11 & 0.94 & 18 & 18 \\
\hline Large & 9 & 6.25 & 2.75 & 1.21 & 6 & 3.25 & 2.75 & 2.3 & 1 & 5.5 & -4.5 & 3.68 & 1 & 2 & -1 & 0.5 & 17 & 17 \\
\hline Coordinated & 9 & 6.62 & 2.38 & 0.58 & 1 & 3.44 & -2.44 & 1.73 & 7 & 5.82 & 1.18 & 0.24 & 1 & 2.12 & -1.12 & 0.59 & 18 & 18 \\
\hline Sum & 25 & 25 & & 5.81 & 13 & 13 & & 5.94 & 22 & 22 & & 7.57 & 8 & 8 & & 4.83 & 68 & 68 \\
\hline
\end{tabular}

Correlation coefficient and Chi-square in character size is 0.51 and 24.15 respectively. Calculated Chi-square is greater than table Chi-square, so research hypothesis is accepted with $99 \%$ confidence level.

According to variable classes (Table 5), character size in unstable extroverts is coarse and uneven, in stable extraversions is bold, in unstable introverts is fine and uncoordinated, in stable introverts is fine. In general, extraversions, introversions and unstable people write coarse, fine and uneven respectively. Higher score of persons in $\mathrm{N}$ scale leads to higher mismatch of character size.

Table 6. Chi-square for distance between rows variable.

\begin{tabular}{|c|c|c|c|c|c|c|c|c|c|c|c|c|c|c|c|c|c|c|}
\hline \multirow[t]{2}{*}{ Classes } & \multicolumn{4}{|c|}{ Unstable extrovert } & \multicolumn{3}{|c|}{ Stable extrovert } & \multicolumn{5}{|c|}{ Unstable introvert } & \multicolumn{3}{|c|}{ Stable introvert } & & \multicolumn{2}{|c|}{ Total } \\
\hline & $\mathbf{O}$ & $\mathbf{E}$ & $O-E$ & $\frac{(\boldsymbol{O}-E)^{2}}{E}$ & O & $\mathbf{E}$ & $O-E$ & $\frac{(\boldsymbol{O}-E)^{2}}{E}$ & 0 & $\mathbf{E}$ & $O-E$ & $\frac{(O-E)^{2}}{E}$ & O & $\mathbf{E}$ & $O-E$ & $\frac{(O-E)^{2}}{E}$ & $\mathbf{O}$ & $\mathbf{E}$ \\
\hline Low & 4 & 6.25 & -2.25 & 0.81 & 1 & 3.25 & -2.25 & 1.58 & 7 & 5.5 & 1.5 & 0.4 & 5 & 2 & 3 & 4.5 & 17 & 17 \\
\hline Balanced & 6 & 6.98 & -0.98 & 0.14 & 10 & 3.63 & 6.37 & 11.17 & 2 & 6.17 & -4.17 & 2.8 & 1 & 2.24 & -1.24 & 0.68 & 19 & 19 \\
\hline High & 5 & 3.31 & 1.96 & 0.86 & 2 & 1.72 & 0.28 & 0.045 & 1 & 2.9 & -1.9 & 1.24 & 1 & 1.06 & 0.06 & 0.03 & 9 & 9 \\
\hline Unbalanced & 10 & 8.45 & 1.55 & 0.28 & - & 4.4 & -4.4 & 4.4 & 12 & 7.45 & 4.55 & 2.77 & 1 & 2.7 & -1.7 & 1.07 & 23 & 23 \\
\hline Sum & 25 & 25 & & 2.09 & 13 & 13 & & 17.19 & 22 & 22 & & 7.21 & 8 & 8 & & 6.25 & 68 & 68 \\
\hline
\end{tabular}

Correlation coefficient and Chi-square in rows distance is 0.57 and 32.74 respectively. Considering the domain freedom of 9, Chi-square is 21.67. Calculated Chi-square is greater than table Chi-square, so research hypothesis is accepted with $99 \%$ confidence level.

According to variable classes (Table 6), rows distance in unstable extroverts is often unbalanced and high, in stable introverts is unbalanced and low and in stable introverts is low. In general, rows distance in extraversions is high and in introversions is low. Persons who achieved greater $\mathrm{N}$ have unbalanced row distance.

Table 7. Chi-square for distance between words variable.

\begin{tabular}{|c|c|c|c|c|c|c|c|c|c|c|c|c|c|c|c|c|c|c|}
\hline \multirow[t]{2}{*}{ Class } & \multicolumn{3}{|c|}{ Unstable extrovert } & \multicolumn{5}{|c|}{ Stable extrovert } & \multicolumn{4}{|c|}{ Unstable introvert } & \multicolumn{4}{|c|}{ Stable introvert } & \multicolumn{2}{|c|}{ total } \\
\hline & O & $\mathbf{E}$ & $O-E$ & $\frac{(\boldsymbol{O}-E)^{2}}{E}$ & $\mathbf{O}$ & $\mathbf{E}$ & $\boldsymbol{O}-\boldsymbol{E}$ & $\frac{(\boldsymbol{O}-E)^{2}}{E}$ & O & $\mathbf{E}$ & $\boldsymbol{O}-\boldsymbol{E}$ & $\frac{(\boldsymbol{O}-E)^{2}}{E}$ & O & $\mathbf{E}$ & $\boldsymbol{O}-\boldsymbol{E}$ & $\frac{(\boldsymbol{O}-E)^{2}}{E}$ & O & $\mathbf{E}$ \\
\hline Low & 1 & 4.04 & -3.04 & 2.28 & 1 & 2.1 & -1.1 & 0.57 & 6 & 3.55 & 2.45 & 1.7 & 3 & 1.3 & 1.7 & 2.22 & 11 & 11 \\
\hline Balanced & 1 & 5.15 & -4.15 & 3.34 & 6 & 2.7 & 3.3 & 4.03 & 3 & 4.53 & -1.53 & 0.516 & 4 & 1.65 & 2.35 & 3.34 & 14 & 14 \\
\hline High & 15 & 10.66 & 4.34 & 1.76 & 6 & 5.5 & 0.45 & 0.036 & 8 & 9.4 & -1.4 & 0.2 & - & 3.4 & -3.4 & 3.4 & 29 & 29 \\
\hline Unbalanced & 8 & 5.15 & 2.85 & 1.577 & - & 2.7 & 2.7 & 2.7 & 5 & 4.52 & 0.48 & 0.05 & 1 & 1.65 & -0.65 & 0.25 & 14 & 14 \\
\hline Sum & 25 & 25 & & 8.96 & 13 & 13 & & 7.33 & 22 & 22 & & 2.46 & 8 & 8 & & 9.21 & 68 & 68 \\
\hline
\end{tabular}

Correlation coefficient and Chi-square in words distance variable is 0.53 and 27.96 respectively. Considering the domain freedom of 9, Chi-square is 21.67. Calculated Chisquare is greater than table Chi-square, so research hypothesis is accepted with $99 \%$ confidence level.

According to variable classes (Table 7), words distance in unstable extroverts is high and unbalanced, in stable extraversions is high and balanced. Words distance in unstable introverts is high and low (unbalanced), in stable introverts is low and balanced. Persons who achieved higher score of $\mathrm{N}$, have unbalanced rows distance. 
Table 8. Chi-square for distance between letters variable.

\begin{tabular}{llllllllllllllllllll}
\hline Class & \multicolumn{1}{c}{ Unstable extrovert } & \multicolumn{4}{c}{ Stable extrovert } & \multicolumn{4}{c}{ Unstable introvert } & \multicolumn{3}{c}{ Stable introvert } \\
\hline & $\mathbf{O}$ & $\mathbf{E}$ & $\boldsymbol{O}-\boldsymbol{E}$ & $\frac{(\boldsymbol{O}-\boldsymbol{E})^{2}}{\boldsymbol{E}}$ & $\mathbf{O}$ & $\mathbf{E}$ & $\boldsymbol{O}-\boldsymbol{E}$ & $\frac{(\boldsymbol{O}-\boldsymbol{E})^{2}}{\boldsymbol{E}}$ & $\mathbf{O}$ & $\mathbf{E}$ & $\boldsymbol{O}-\boldsymbol{E}$ & $\frac{(\boldsymbol{O}-\boldsymbol{E})^{2}}{\boldsymbol{E}}$ & $\mathbf{O}$ & $\mathbf{E}$ & $\boldsymbol{O}-\boldsymbol{E}$ & $\frac{(\boldsymbol{O}-\boldsymbol{E})^{2}}{\boldsymbol{E}}$ & $\mathbf{O}$ & $\mathbf{E}$ \\
\hline Low & - & 5.5 & -5.5 & 5.5 & - & 2.9 & -2.9 & 2.9 & 11 & 4.85 & 6.15 & 7.79 & 4 & 1.8 & 2.2 & 2.68 & 15 & 15 \\
Balanced & 1 & 3.3 & -2.3 & 1.6 & 3 & 1.72 & 1.28 & 0.95 & 2 & 2.91 & -0.91 & 0.28 & 3 & 1.06 & 1.94 & 3.5 & 9 & 9 \\
High & 18 & 11.8 & 6.2 & 3.25 & 10 & 6.1 & 3.9 & 2.49 & 3 & 10.35 & -7.35 & 5.21 & 1 & 3.75 & -2.75 & 2 & 32 & 32 \\
Unbalanced & 6 & 4.4 & 1.6 & 0.58 & - & 2.3 & -2.3 & 2.3 & 6 & 3.9 & 2.1 & 1.13 & - & 1.4 & -1.4 & 1.4 & 12 & 12 \\
Sum & 25 & 25 & & 10.93 & 13 & 13 & & 8.64 & 22 & 22 & & 14.41 & 8 & 8 & & 9.58 & 68 & 68 \\
\hline
\end{tabular}

Correlation coefficient and Chi-square in words distance variable is 0.62 and 43.56 respectively. Considering the domain freedom of 9, Chi-square is 21.67. Calculated Chisquare is greater than table Chi-square, so research hypothesis is accepted with $99 \%$ confidence level.

Letters distance in unstable extroverts is high with relative unbalanced mode. Letters distance in stable extraversions is high and effects of balance are obvious. Letters distance in unstable introverts is low and there is balanced mode. In persons who achieved higher score of $\mathrm{N}$, letters distance is high and low (unbalanced) and balance distance in rows is observed in person with low score of $\mathrm{N}$.

Table 9. Chi-square for baseline variable.

\begin{tabular}{|c|c|c|c|c|c|c|c|c|c|c|c|c|c|c|c|c|c|c|}
\hline \multirow[t]{2}{*}{ Line type } & \multicolumn{3}{|c|}{ Unstable extrovert } & \multicolumn{5}{|c|}{ Stable extrovert } & \multicolumn{3}{|c|}{ Unstable introvert } & \multicolumn{4}{|c|}{ Stable introvert } & \multicolumn{3}{|c|}{ Total } \\
\hline & $\mathbf{O}$ & $\mathbf{E}$ & $O-E$ & $\frac{(\boldsymbol{O}-E)^{2}}{E}$ & 0 & $\mathbf{E}$ & $O-E$ & $\frac{(O-E)^{2}}{E}$ & $\mathbf{O}$ & $\mathbf{E}$ & $\boldsymbol{O}-\boldsymbol{E}$ & $\frac{(\boldsymbol{O}-E)^{2}}{E}$ & $\mathbf{O}$ & $\mathbf{E}$ & $\boldsymbol{O}-\boldsymbol{E}$ & $\frac{(\boldsymbol{O}-E)^{2}}{E}$ & $\mathbf{O}$ & $\mathbf{E}$ \\
\hline Horizontal & 5 & 6.61 & -1.61 & 0.4 & 9 & 3.4 & 5.5 & 8.93 & 1 & 5.82 & -4.82 & 4 & 3 & 2.12 & 0.88 & 0.36 & 18 & 18 \\
\hline $\begin{array}{l}\text { Undifferentia } \\
\text { ted }\end{array}$ & 8 & 5.51 & 2.49 & 1.12 & 1 & 2.8 & -1.8 & 1.2 & 6 & 4.85 & 1.15 & 0.27 & - & 1.76 & -1.76 & 1.76 & 15 & 15 \\
\hline Upward & 3 & 1.83 & 1.17 & 0.75 & - & 0.95 & -0.95 & 0.95 & 2 & 1.62 & 0.38 & 0.09 & - & 0.6 & -0.6 & 0.6 & 5 & 5 \\
\hline Downward & 6 & 8.45 & -2.45 & 0.71 & 2 & 4.4 & 2.4 & 1.31 & 11 & 7.44 & 3.56 & 1.7 & 4 & 2.7 & 1.3 & 0.62 & 23 & 23 \\
\hline Convex & 2 & 1.1 & 0.9 & 0.73 & - & 0.6 & -0.6 & 0.6 & - & 0.97 & -0.97 & 0.97 & 1 & 0.35 & 0.65 & 1.2 & 3 & 3 \\
\hline Concave & 1 & 1.5 & -0.5 & 0.16 & 1 & 0.76 & 0.24 & 0.07 & 2 & 1.3 & 0.7 & 0.38 & - & 0.47 & -0.47 & 0.47 & 4 & 4 \\
\hline Total & 25 & 25 & & 3.86 & 13 & 13 & & 13.06 & 22 & 22 & & 7.41 & 8 & 8 & & 5.01 & 68 & 68 \\
\hline
\end{tabular}

Correlation coefficient and Chi-square in words distance variable is 0.54 and 29.34 respectively. Considering the domain freedom of 15, Chi-square is 25.15. Calculated Chisquare is greater than table Chi-square, so research hypothesis is accepted with $95 \%$ confidence level.

According to baseline variable classes (Table 9), unstable extroverts in baseline classes are undifferentiated, downwards and horizontal which undifferentiated baseline is more obvious. Baseline in stable extraversions is often horizontal. Unstable and stable introverts have downwards baseline. In persons who achieved higher score of N, baseline is undifferentiated and fix baseline (downwards and horizontal) is observed in person with low score of $\mathrm{N}$.

Table 10. Chi-square for stand line variable.

\begin{tabular}{|c|c|c|c|c|c|c|c|c|c|c|c|c|c|c|c|c|c|c|}
\hline \multirow[b]{2}{*}{ Line type } & \multicolumn{3}{|c|}{ Unstable extrovert } & & \multicolumn{3}{|c|}{ Stable extrovert } & \multirow[b]{2}{*}{$\frac{(\boldsymbol{O}-E)^{2}}{E}$} & \multicolumn{3}{|c|}{ Unstable introvert } & \multicolumn{4}{|c|}{ Stable introvert } & \multicolumn{3}{|c|}{ Total } \\
\hline & $\mathbf{O}$ & $\mathbf{E}$ & $O-E$ & $\frac{(\boldsymbol{O}-E)^{2}}{E}$ & $\mathbf{O}$ & $\mathbf{E}$ & $O-E$ & & $\mathbf{O}$ & $\mathbf{E}$ & $O-E$ & $\frac{(O-E)}{E}$ & 0 & $\mathbf{E}$ & $O-E$ & $\frac{(\boldsymbol{O}-E)^{2}}{E}$ & $\mathbf{O}$ & $\mathbf{E}$ \\
\hline $\begin{array}{l}\text { Right Angle } \\
\text { (orthogonal) }\end{array}$ & 1 & 3.7 & -2.7 & 1.97 & 2 & 1.9 & 0.1 & 0.005 & 4 & 3.2 & 0.8 & 0.2 & 3 & 1.2 & 1.8 & 2.7 & 10 & 10 \\
\hline $\begin{array}{l}\text { orthogonal to } \\
\text { left inclined }\end{array}$ & 8 & 3 & 5 & 8.33 & - & 1.5 & -1.5 & 1.5 & - & 2.5 & -2.5 & 2.5 & - & 1 & -1 & 1 & 8 & 8 \\
\hline $\begin{array}{l}\text { orthogonal to } \\
\text { right inclined }\end{array}$ & 4 & 3.7 & 0.3 & 0.02 & 1 & 1.9 & -0.9 & 0.42 & 5 & 3.2 & 1.8 & 1.01 & - & 1.2 & -1.2 & 1.2 & 10 & 10 \\
\hline $\begin{array}{l}\text { Tolerance from } \\
\text { inclined to right } \\
\text { and left }\end{array}$ & 9 & 5.1 & 3.9 & 2.98 & 2 & 2.7 & -0.7 & 0.18 & 3 & 4.5 & -1.5 & 0.5 & - & 1.6 & -1.6 & 1.6 & 14 & 14 \\
\hline inclined to right & - & 6.6 & -6.6 & 6.6 & 3 & 3.5 & -0.5 & 0.07 & 10 & 6 & 4 & 2.66 & - & 2 & 3 & 4.5 & 18 & 18 \\
\hline inclined to left & 3 & 2.9 & 0.1 & 0.003 & 5 & 1.5 & 3.5 & 8.16 & - & 2.6 & -2.6 & 2.6 & 5 & 1 & $1-$ & 1 & 8 & 8 \\
\hline Total & 25 & 25 & & 19.9 & 13 & 13 & & 10.33 & 22 & 22 & & 9.47 & 8 & 8 & & 12 & 68 & 68 \\
\hline
\end{tabular}

Correlation coefficient and Chi-square in stand line variable is 0.65 and 51.7 respectively. Considering the domain freedom of 15, Chi-square is 30.58. Calculated Chisquare is greater than table Chi-square, so research hypothesis is accepted with $99 \%$ confidence level.
Unstable extroverts in stand line are in tolerance toward right and left in different word (author try to maintain its adequacy). Stand lines in stable extraversions are towards left. Stand line in unstable introverts are inclined to right or are in tolerance from vertical to right. In stable introverts, 
stand line are more inclined to right. In persons who achieved higher score in $\mathrm{N}$ scale, stand lines thorough out the text in different words are inclined in different directions and in persons who achieved higher score in $\mathrm{N}$ scale, stand lines are fix and inclined in specific direction.

Table 11. Chi-square for punctuation variable.

\begin{tabular}{|c|c|c|c|c|c|c|c|c|c|c|c|c|c|c|c|c|c|c|}
\hline \multirow[b]{2}{*}{ Classes } & \multicolumn{4}{|c|}{ Unstable extrovert } & \multicolumn{3}{|c|}{ Stable extrovert } & \multicolumn{5}{|c|}{ Unstable introvert } & \multicolumn{3}{|c|}{ Stable introvert } & \multicolumn{3}{|c|}{ Total } \\
\hline & $\mathbf{O}$ & $\mathbf{E}$ & $\boldsymbol{O}-\boldsymbol{E}$ & $\frac{(\boldsymbol{O}-E)^{2}}{E}$ & $\mathbf{O}$ & $\mathbf{E}$ & $\boldsymbol{O}-\boldsymbol{E}$ & $\frac{(\boldsymbol{O}-E)^{2}}{E}$ & $\mathbf{O}$ & $\mathbf{E}$ & $\boldsymbol{O}-\boldsymbol{E}$ & $\frac{(O-E)^{2}}{E}$ & $\mathbf{O}$ & $\mathbf{E}$ & $\boldsymbol{O}-\boldsymbol{E}$ & $\frac{(\boldsymbol{O}-E)^{2}}{E}$ & $\mathbf{O}$ & $\mathbf{E}$ \\
\hline High & 4 & 2.2 & 1.8 & 1.47 & 2 & 1.15 & 0.85 & 0.63 & - & 1.94 & -1.94 & 1.94 & - & 0.71 & - & 0.71 & 6 & 6 \\
\hline Low & 2 & 8.46 & -6.46 & 4.932 & 1 & 4.4 & -3.4 & 2.63 & 15 & 7.44 & 7.56 & 7.68 & 5 & 2.7 & 2.3 & 1.959 & 23 & 23 \\
\hline Correct & 8 & 7.35 & 0.65 & 0.057 & 10 & 3.82 & 6.18 & 9.99 & 1 & 6.5 & -5.5 & 4.65 & 1 & 2.35 & -1.35 & 0.775 & 20 & 20 \\
\hline Thrown & 6 & 4.05 & 1.95 & 0.938 & - & 2.1 & -2.1 & 2.1 & 4 & 3.55 & 0.45 & 0.057 & 1 & 1.3 & -0.3 & 0.069 & 11 & 11 \\
\hline $\begin{array}{l}\text { Some High } \\
\text { and some low }\end{array}$ & 5 & 2.94 & -0.88 & 0.263 & - & 1.53 & -1.53 & 1.53 & 2 & 2.58 & -0.58 & 0.13 & 1 & 0.95 & 0.05 & 0.002 & 8 & 8 \\
\hline
\end{tabular}

Correlation coefficient and Chi-square in punctuation variable is 0.62 and 42.51 respectively. Considering the domain freedom of 12, Chi-square is 26.22. Calculated Chisquare is greater than table Chi-square, so research hypothesis is accepted with $99 \%$ confidence level.

According to table11, in unstable extroverts, points are in correct location and thrown. Punctuation in stable extraversions is in correct location too. Punctuation in introverts is low and next to words. Thrown points are more in persons who achieved higher score in $\mathrm{N}$ scale (instability). In persons who achieved lower score in $\mathrm{N}$ scale, points are located in correct place of their personality.

\section{Conclusion}

Graphology tests in comparison with other tests is cheaper and faster and provide information quickly about personality, emotions, consciousness, intelligence, social adjustment, talent, creativity and other individuals characteristics. According to the results, personality of people couldn't be realized based on just one variable and different variables of personality must taking into account in the handwriting judge. Summing up the different variables in handwriting, leads us to the conclusion. It should be noted that many factors are involved in this study as disturbing factors and could affect the result of the investigation. In the case of the character size and personality, Rassam [14] confirms the results of this research. He proved that there is relation between handwriting and extraversion, and length of handwriting in extraversions is more, other researcher such as Eysenck [8] confirm this result. Other research on the handwriting and sign is conducted by [1] in Iran and results support the findings of this study. In general, it may be judged that (a) In society, number of people with unstable extrovert personality is more; (b) the amount of instable people is more than stable and (c) the number of extroverts is more than introverts.

\section{Limitations of This Study}

a) Lack of the researcher concentration in the field of precision measurement equipment in research, including freedom of paper selection, freedom in selection text (since normal writing mode is required). Freedom of writer to select paper, color, size and type of paper, can help the analyzer to learn more about him. Paper without line is good. Large paper is a sign of desire to progress and selfconfidence. Small papers are chosen by materialist or those who can't properly estimate the required area for writing. Selection of underlined paper (including baseline and margin) is a sign of people who need guidance and support and has tendency to obey the regulations and values. Rough paper is chosen by challenger and individuals who likes to fight. Also quiet and gentle and sometimes impatient and bored people prefer smooth paper. Color of the selected paper is effective too.

b) Geography result is not always from moral origins and even most of them may be related to status of the person in writing. Mental condition of authors in writing position has specific benefits in forensic psychology and criminal law.

c) Graphology is not always accurate. Behavior and personality of people are changing constantly, and therefore if the handwriting is used to find the personality, handwriting samples should study in a period of time (such as perennial).

Suggestions for those who are interested to study in this field:

- Select larger sample size (especially in the case of color variable).

- Test the Health Assessment Questionnaire, NEO and MMPI.

- Punctuation method (single-point, two points, three points, attaching methods of points, separating methods of points, etc.) is a big topic and can be the subject of a comprehensive study.

\section{References}

[1] Agha yousefi, A. R. 2009. Personality analysis based on handwriting. Lamak publication, Qom.

[2] Aziz, M. (2009). Handwriting analysis, available at: $\mathrm{http} / /$ mohsenazizi.blagfa.com. 
[3] Bouadjenek, Nesrine, Hassiba Nemmour and Youcef Chibani (2015). Robust soft-biometrics prediction from off-line handwriting analysis. Applied Soft Computing, doi:10.1016/j.asoc.2015.10.021 (In Press).

[4] Cronje, Pierre E. and Hester E Roets (2013). Graphology in Psychological Assessment: A Diagnosis in Writing. Universal Journal of Psychology, 1 (4): 163-168.

[5] Crowley, Tony (1991). The Influence of Social Desirability on the Relationships between Handwriting and Personal Qualities. Personality and Individual Differences, 12 (9): 881885 .

[6] Delavar, A. 2008. Applied Statistic and Probability in psychology and educative sciences. Roshd Publication, Tehran.

[7] Diagram Grouf (1999), Handwriting analysis, Sterling.

[8] Eysenck, H. J. (1953). The structure of human personality. Wiley, New York.
[9] Fathi Ashtiani, S. 2009. Psychological tests. Be'sat Publication, Tehran.

[10] Ganji, H. 2007. Personality evaluation. Savalan Publication, Tehran.

[11] Hilgard E. Atkinson R. C. (editor: Atkinson L. R.). (2006). Hilgard's introduction to psychology. Translated by barahani, M. T. Roshd Publication, Tehran.

[12] Kaviani, Hossein (2003). Bio Theory of Personality. Sana Publication. Tehran.

[13] Pervin, Lawerence A., John Elliorby (2007). Personality; Theory and Research. Translated by Mohammad Jafar Javadi and Parvin Kadivar. Aeezh Publication, Tehran.

[14] Rassam, Amir Reza (2006). The relationship of handwriting length with personality characteristics of introvert and extrovert. Master's Thesis. Payamenoor University, Miyaneh.

[15] TenHouten W. D. (2011). Handwriting and Creativity. Encyclopedia of Creativity (Second Edition). Academic Press. 